\title{
MONITORING GROUND SUBSIDENCE IN AREAS COVERED BY DENSE VEGETATION USING TERRASAR-X IMAGES: A CASE STUDY OF HANGZHOU
}

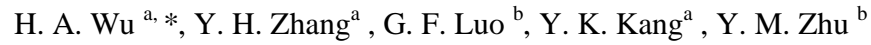 \\ ${ }^{a}$ Chinese Academy of Surveying and Mapping, 100830 Haidian District, Beijing, China - (wuha, yhzhang) @ casm.ac.cn, \\ 331043369@qq.com, \\ b Zhejiang Academy of Surveying and Mapping, 310012 Xihu District, Hangzhou, China - 1824542572@qq.com, \\ 372819767@qq.com
}

Commission VII, WG VII/2

KEY WORDS: Ground subsidence, InSAR, high resolution, TerraSAR-X, Hangzhou

\begin{abstract}
:
Hangzhou, the capital of Zhejiang province has suffered serious ground subsidence during the past several decades, due to long term over-exploration of groundwater. In this paper, the time series InSAR technique using high resolution SAR images is investigated for the generation of subsidence maps over Hangzhou region. 29 TerraSAR-X images acquired from May 2012 to Sep 2015 are used. The results show that serious subsidence has mainly taken place in suburban area, including Yuhang district, Xiaoshan district and Binjiang district. 4 subsidence centers are discovered, namely Tangqi town in Yuhang with an average subsiding velocity of -29.6 $\mathrm{mm} /$ year, Xintang (-30.7 mm/year) in Xiaoshan, Zhujiaqiao town $(-25.6 \mathrm{~mm} / \mathrm{year})$ in Xiaoshan, and Miaohouwang town ($30.1 \mathrm{~mm} /$ year) in Binjiang. The urban area is stable and ground rebound even take place in some places. The results are compared with 19 levelling measurements. The RMS error between them is $2.9 \mathrm{~mm} /$ year, which demonstrates that the high resolution TerraSAR-X images has good accuracy for subsidence monitoring in the southeast of China, covered by dense vegetation.
\end{abstract}

\section{INTRODUCTION}

Hangzhou is a typical southern city with large water demands in China. For long time, domestic water are mainly provided by the Qiantang River in the plain region and karst water or fissure water in the mountain and hilly region. However, with the fast increase of population, the rapid development of industrial and agricultural production, the industrial pollution discharge in the Qiantang River has been worsening day by day. Pollutant emissions significantly exceed the environmental capacity and self purification ability. Thus groundwater over-exploitation is increasing which induce ground subsidence in this city.

It is necessary to monitor the ground subsidence accurately and duly. Traditional ways of monitoring ground deformation are leveling and GPS measurement. They have the advantage of high accuracy. However, they are very costly and cannot achieve enough spatial sampling density. With the development of radar remote sensing technique, differential interferometric SAR (DInSAR) has been playing an important role in monitoring ground deformation.

However, for long term deformation, conventional 2-pass or 3pass DInSAR can be easily affected by temporal or geometric de-correlation which degrades the interferometric phase and makes it difficult to extract useful information (Ferretti 1999). To solve this problem, some advances in this field have been introduced based on point target analysis, including permanent scatterers (PS) method (Ferretti 2000 and 2001, Vilardo 2009, Zhang 2011), small baseline subsets (SBAS) method (Berardino 2002, Casu 2008) and coherent points (CP) method (Mora 2003, Wu 2011, Zhang 2012). In this paper, we investigate the small baseline time series InSAR technique for the generation of deformation maps of Hangzhou city. 29 high resolution TerraSAR-X SAR images acquired from May 2012 to Sep 2015 are used.

\section{STUDY AREA AND DATASETS}

\subsection{Study area}

The downtown and surrounding areas of Hangzhou city was selected as the study area, with a length of $58 \mathrm{~km}$ and a width of $32 \mathrm{~km}$. The central geographic coordinates of the area is $30.40^{\circ} \mathrm{N}$ and $120.28^{\circ} \mathrm{E}$. Figure 1 shows the coverage of study area with the average SAR amplitude image. For Hangzhou is located in the southern China, dense vegetation and water surfaces are distributed in large area, which make InSAR difficult to maintain high coherence on the interferograms.

\subsection{Datasets}

SAR images used in this paper include 29 TerraSAR-X single look complex (SLC) images, acquired from May 2012 to Sep 2015. These data were obtained in descending direction, with an incidence angle of $35.28^{\circ}$. The azimuth resolution is about $1.99 \mathrm{~m}$ and the range resolution is about $0.91 \mathrm{~m}$. Table 1 shows the temporal and perpendicular baselines of these SAR data.

In addition, to remove the topographic phase from interferograms, digital elevation model (DEM) generated by Shuttle Radar Topography Mission (SRTM) with 3 arc-second resolution (about $90 \mathrm{~m}$ ) is used. To validate the final deformation results retrieved by time series InSAR, 19 leveling measurements from 2012 to 2015 are collected.

\footnotetext{
* Corresponding author. Tel: 86-10-63880521, Fax: 86-10-63880535.
} 


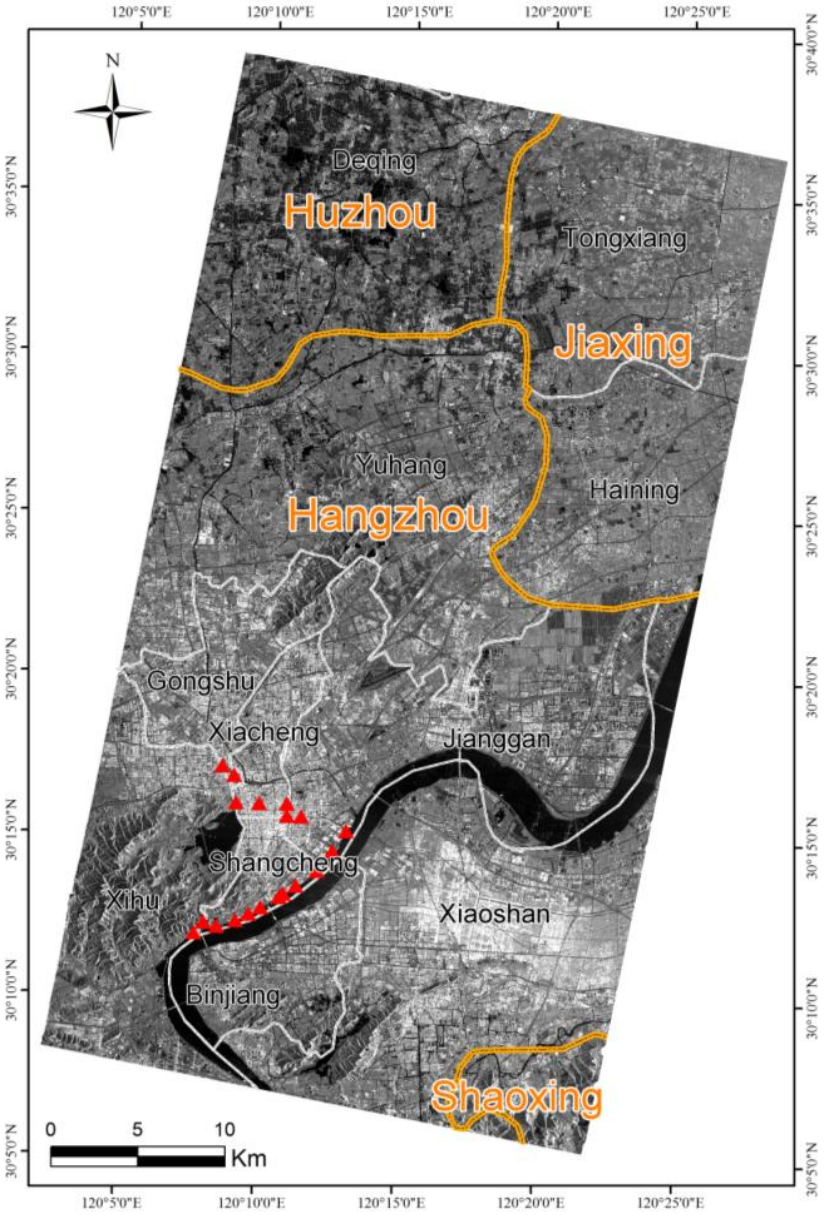

Figure 1. The average amplitude image of 29 TerraSAR-X images and the distribution of levelling points (red triangle)

\section{METHODS}

There are two parts contained in the small baseline time series InSAR technique, including linear deformation retrieval and non-linear deformation retrieval. Let us start our analysis by considering N SAR images acquired at the ordered times. Based on the principle of small spatial and temporal baselines, we can generate $\mathrm{M}$ interferograms. Before linear deformation retrieval, high coherence point targets are selected according to pixel's coherence stability by setting a suitable coherence threshold for the temporal mean coherence image and amplitude stability by setting a threshold for amplitude difference dispersion index. Based on these point targets, differential phase are connected with Delaunay triangulation. Thus the phase slope between two neighboring points $\left(x_{m}, y_{m}\right),\left(x_{n}, y_{n}\right)$ on an edge can be expressed as

$$
\begin{aligned}
\delta \phi_{\text {dif }}\left(x_{m}, y_{m}, x_{n}, y_{n}, T_{i}\right)= & \frac{4 \pi}{\lambda} \cdot T_{i} \cdot\left[v\left(x_{m}, y_{m}\right)-v\left(x_{n}, y_{n}\right)\right] \\
& +\frac{4 \pi}{\lambda} \cdot \frac{b\left(T_{i}\right)}{r\left(T_{i}\right) \sin \left(\theta_{i}\right)} \cdot\left[\varepsilon\left(x_{m}, y_{m}\right)-\varepsilon\left(x_{n}, y_{n}\right)\right] \\
& +\left[\beta\left(x_{m}, y_{m}\right)-\beta\left(x_{n}, y_{n}\right)\right] \\
& +\left[\alpha\left(x_{m}, y_{m}\right)-\alpha\left(x_{n}, y_{n}\right)\right] \\
& +\left[n\left(x_{m}, y_{m}\right)-n\left(x_{n}, y_{n}\right)\right]
\end{aligned}
$$

Table 1. List of the perpendicular and temporal baselines of 29 TerraSAR-X images

\begin{tabular}{|c|c|c|c|}
\hline$\#$ & Date & $\begin{array}{c}\text { Perpendicular } \\
\text { baseline } / \mathrm{m}\end{array}$ & $\begin{array}{c}\text { Temporal } \\
\text { Baseline } / \text { day }\end{array}$ \\
\hline 1 & 20120515 & 0 & 0 \\
2 & 20120628 & 22 & 44 \\
3 & 20120731 & 68 & 77 \\
4 & 20120902 & 19 & 110 \\
5 & 20121016 & 75 & 154 \\
6 & 20121118 & 113 & 187 \\
7 & 20121221 & 138 & 220 \\
8 & 20130123 & 165 & 253 \\
9 & 20130225 & 146 & 286 \\
10 & 20130421 & 157 & 341 \\
11 & 20130626 & -86 & 407 \\
12 & 20130729 & -10 & 440 \\
13 & 20130922 & 63 & 495 \\
14 & 20131105 & 254 & 539 \\
15 & 20140317 & 167 & 671 \\
16 & 20140408 & 163 & 693 \\
17 & 20140522 & 201 & 737 \\
18 & 20140613 & 148 & 759 \\
19 & 20140705 & -4 & 781 \\
20 & 20141001 & 139 & 869 \\
21 & 20141023 & 61 & 891 \\
22 & 20141114 & 39 & 913 \\
23 & 20141206 & 230 & 935 \\
24 & 20150119 & 316 & 979 \\
25 & 20150210 & 40 & 1001 \\
26 & 20150509 & 21 & 1089 \\
27 & 20150622 & 80 & 1133 \\
28 & 20150827 & 37 & 1199 \\
29 & 20150918 & 2 & 1221 \\
\hline
\end{tabular}

where $\mathcal{E}$ and $v$ are the height error and linear deformation velocity; $\left(x_{m}, y_{m}\right)$ and $\left(x_{n}, y_{n}\right)$ are pixel position coordinates; $T_{i}$ is the temporal baseline of the ${ }^{i}$ th interferogram; $\beta$ the nonlinear component of deformation; $\alpha$ the atmospheric phase artefacts; and $n$ the decorrelation noise. It is assumed that, within the atmospheric correlation range $1 \sim 3 \mathrm{~km}$, the atmospheric phases are equal, thus the atmospheric components can be neglected. For the linear deformation velocity and height error are constants, thus the above phase slope can be modelled as

$$
\begin{aligned}
\delta \phi_{\text {model }}\left(x_{m}, y_{m}, x_{n}, y_{n}, T_{i}\right)= & \frac{4 \pi}{\lambda} \cdot T_{i} \cdot\left[\Delta v_{\text {model }}(m, n)\right] \\
& +\frac{4 \pi}{\lambda} \cdot \frac{b\left(T_{i}\right)}{r\left(T_{i}\right) \sin \left(\theta_{i}\right)} \cdot\left[\Delta \varepsilon_{\text {model }}(m, n)\right]
\end{aligned}
$$

where $\Delta v$ are $\Delta \varepsilon$ velocity and height error increments, respectively. They can be retrieved by maximizing the following Ensemble Phase Coherence (EPC) (Ferretti, 2000) : 
$\gamma_{\text {model }}\left(x_{m}, y_{m}, x_{n}, y_{n}\right)=\frac{1}{M} \cdot\left|\sum_{i=0}^{M} \exp \left[\begin{array}{l}j \cdot\left(\delta \phi_{d i f}\left(x_{m}, y_{m}, x_{n}, y_{n}, T_{i}\right)\right. \\ \left.-\delta \phi_{\text {model }}\left(x_{m}, y_{m}, x_{n}, y_{n}, T_{i}\right)\right)\end{array}\right]\right|$

where $j$ is the imaginary unit, $M$ is the number of interferograms. When the maximum EPC is close to 1 , the velocity and height error increments are close to the real value. Then, the linear deformation velocity and height error on each point target are obtained by integrating $\Delta v_{\bmod e l}$ and $\Delta \varepsilon_{\bmod e l}$ with EPC over 0.7 from a starting reference point.

To retrieve non-linear deformation, it is necessary to calculate the model phase contributed by linear deformation and height errors. By subtracting the model phase from differential phase, we get residual phases, which mainly include atmospheric phase, non-linear deformation component and phase noises. Phase noises can be reduced by spatial low pass filtering. Atmospheric phase and non-linear deformation can be separated according to their different frequency characteristics in temporal and spatial domains.

\section{RESULTS AND DISCUSSION}

77 interferograms with perpendicular baselines less than $200 \mathrm{~m}$ and temporal baselines within 180 days are generated, as shown in Figure 2. Because of small baselines, all the interferograms can achieve high coherence in most places. Although the study area is covered by dense vegetation and water surfaces, 753788 high coherent point targets are selected with the average coherence above 0.73 and amplitude difference dispersion index below 0.4. Using small baseline InSAR technique described as section 3, average subsidence velocity on point targets are retrieved.

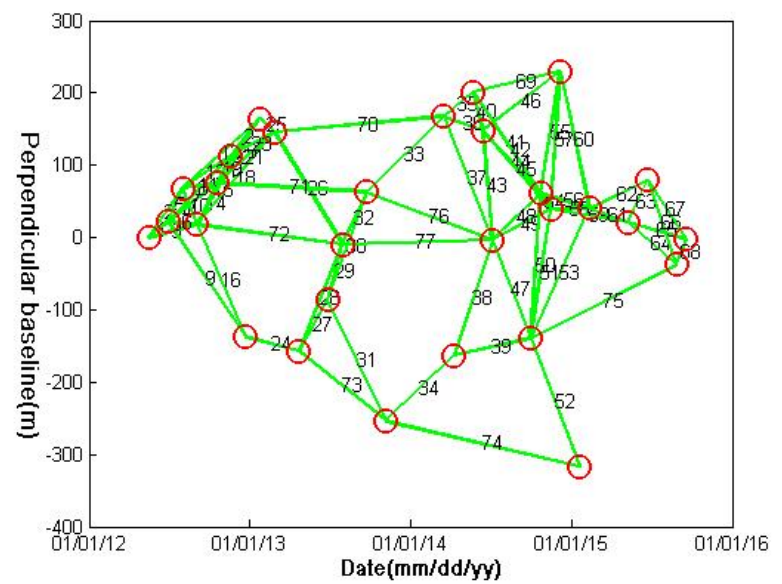

Figure 2. Small baseline interferometric combination between the 29 SAR images

Figure 3 shows the average subsidence velocity in Hangzhou city from May 2012 to Sep 2015, from which we can see that serious subsidence has mainly taken place in suburban area, including Yuhang district, Xiaoshan district and Binjiang district. 4 subsidence centers are discovered, namely Tangqi town in Yuhang with an average subsiding velocity of -29.6 $\mathrm{mm} /$ year, Xintang town $(-30.7 \mathrm{~mm} / \mathrm{year})$ in Xiaoshan, Zhujiaqiao town $(-25.6 \mathrm{~mm} / \mathrm{year})$ in Xiaoshan, and Miaohouwang town $(-30.1 \mathrm{~mm} / \mathrm{year})$ in Binjiang. Compared with the above mentioned suburban area, the ground in urban area including Shangcheng district, Xiacheng district, Xihu district, and Gongshu district is relative stable, and only a few place have subsidence. What's more, ground rebound even takes place in some places in Jianggan district. It may be due to the tough measures taken since 2000 in the urban area against exploitation of groundwater. Except for Hangzhou, we can also find that serious ground subsidence has developed in the nearby Deqing county, Huzhou city. The maximum subsidence velocity is up to $-47.2 \mathrm{~mm} /$ year, which is located in Leidian town.

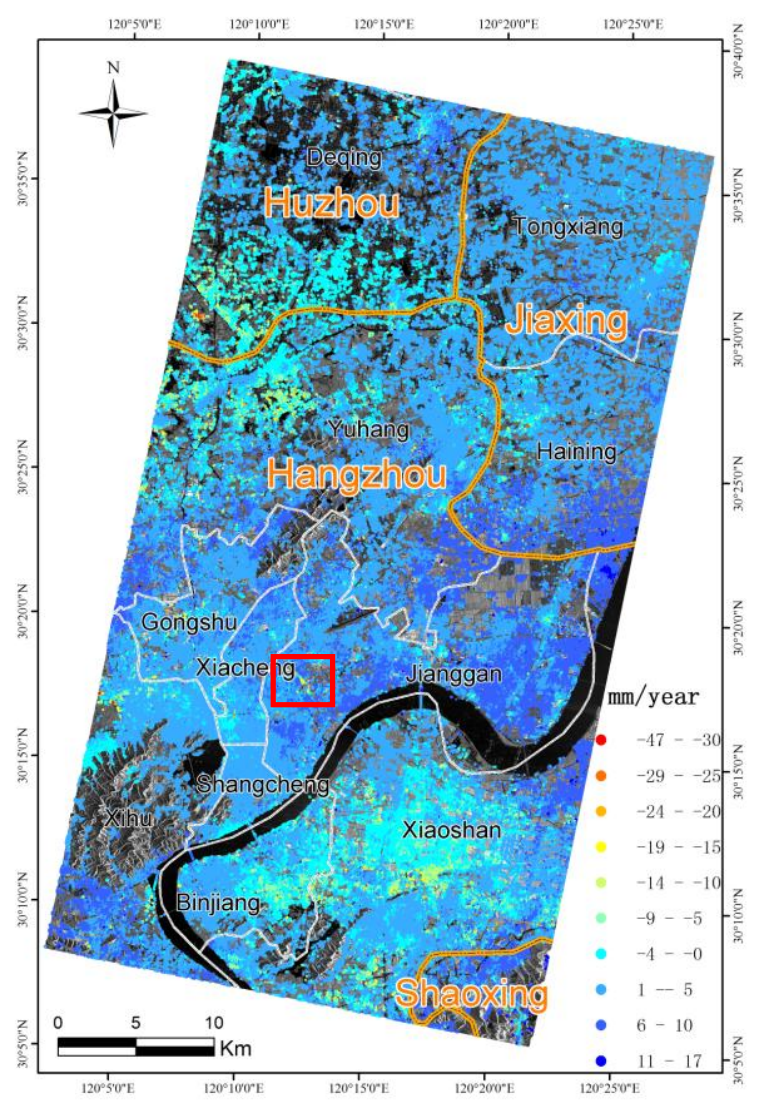

Figure 3. Average subsidence velocity in Hangzhou (20122015). The red block is the coverage of Figure 4.

It is worth noting that obvious subsidence occurs around the Hangzhou East Railway Station as shown in Figure 4, whose coverage is the red block in Figure 3. The maximum subsidence velocity in this region is $-21.0 \mathrm{~mm} / \mathrm{year}$, which may be caused by the construction and operation of the railway station. As we know, the construction of the Hangzhou East Railway Station began on December 27, 2009 and started operation on July 1, 2013. For the station was newly built, the foundation of the station and railway is not stable enough, thus the ground around the station is easy to subside.

To validate the time series InSAR results, 19 levelling measurements in the urban area in Hangzhou distributed as Figure 1 are used. These data are measured from 2012 to 2015. The errors between InSAR results and levelling measurements are shown in Figure 5, from which we can see the absolute error of all 19 points are within $10 \mathrm{~mm} /$ year. 18 points $(94.74 \%)$ have an error ranging from -5 to $5 \mathrm{~mm} /$ year. The error's standard deviation is $2.9 \mathrm{~mm} /$ year, which demonstrates the agreement between them is very good. 


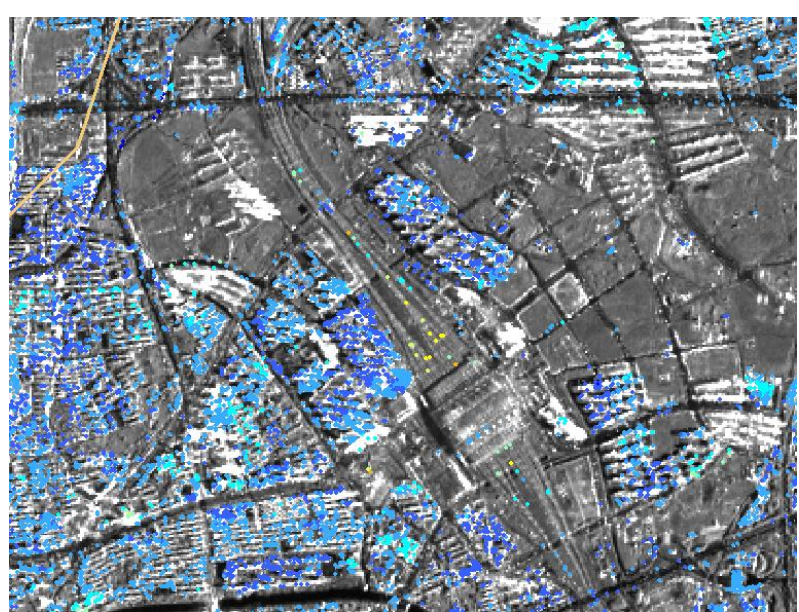

(a)

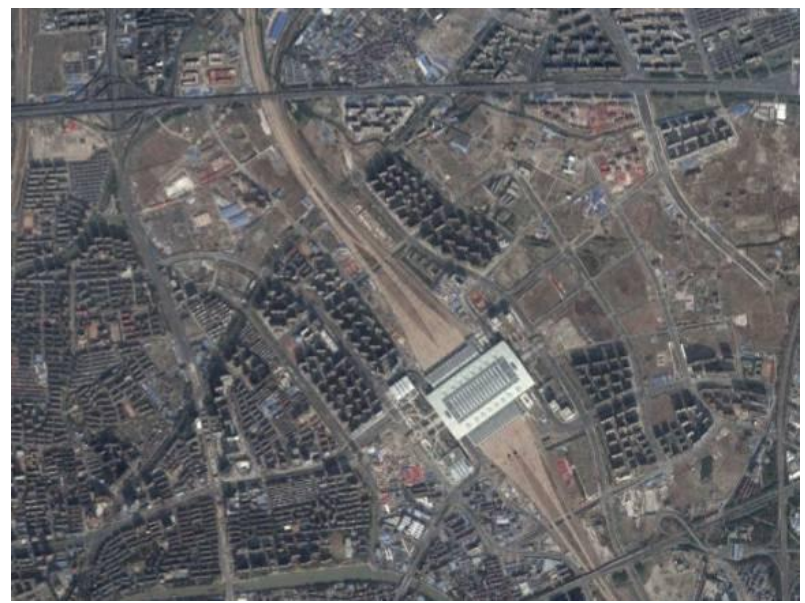

(b)

Figure 4. Average subsidence velocity around the Hangzhou East Railway Station (a) and corresponding optical image (b) provided by Google Earth.

\section{CONCLUSION}

In this study, we applied small baseline time series InSAR technique to investigate ground deformation in Hangzhou city from May 2012 to Sep 2015 by using 29 TerraSAR-X images with high resolution. Results show that the subsidence is mainly taken place in Hangzhou suburban area, including Yuhang district, Xiaoshan district and Binjiang district. The maximum subsidence velocity can reach to $-30.7 \mathrm{~mm} /$ year. The results are validated with 19 levelling measurements. The standard deviation of the errors between the two data is $2.9 \mathrm{~mm} / \mathrm{year}$, which demonstrates that the TerraSAR-X SAR images with short wavelength (X band, $3.1 \mathrm{~cm}$ ) can achieve good accuracy for subsidence monitoring in the southeast of China, covered with lots of vegetation and waters.

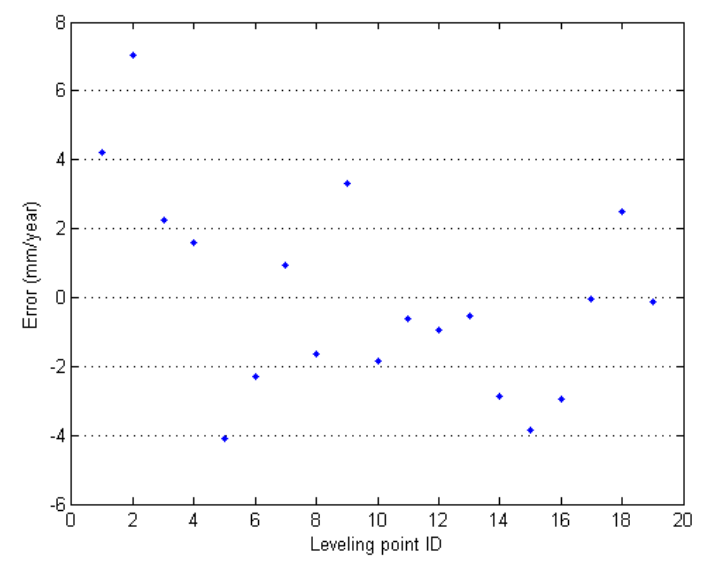

Figure 5. The errors between levelling measurements and InSAR results

\section{ACKNOWLEDGEMENTS}

This research was supported by National Natural Science Foundation of China (No. 41304010, No. 41271430). The leveling measurement data was provided by Zhejiang Academy of Surveying and Mapping. We also thank USGS for supporting the SRTM DEM used in this paper.

\section{REFERENCES}

Ferretti, A., Rocca, F., Prati, C, 1999. Permanent scatterers in SAR interferometry. IGARSS 1999, 3, pp. 1528-1530.

Ferretti, A., Prati, C., Rocca, F, 2009. Nonlinear subsidence rate estimation using permeanent scatterers in differential SAR interferometry. IEEE Trans Geosci Remote Sens, 28(5), pp. 2202-2212.

Ferretti, A., Prati, C., Rocca, F, 2001. Permanent scatterers in SAR interferometry. IEEE Trans Geosci Remote Sens, 39(1), pp. 8-20.

Vilardo, G., Ventura. G., Terranova. C., et al, 2009. Ground deformation due to tectonic, hydrothermal, gravity, hydrogeological, and anthropic processes in the Campania Region (Southern Italy) from Permanent Scatterers Synthetic Aperture Radar Interferometry. Remote Sensing of Environment, 113, pp. 197-212.

Zhang, Y., Zhang, J., Wu, H., et al, 2011. Monitoring of urban subsidence with SAR interferometric point target analysis: A case study in Suzhou, China. International Journal of Applied Earth Observation and Geoinformation, 13, pp. 812-818.

Berardino, P., Fornaro, G., Lanari, R., et al, 2002. A new algorithm for surface deformation monitoring based on small baseline differential SAR interferograms. IEEE Trans Geosci Remote Sens, 40(11), pp. 2375-2383.

Casu. F., Manzo, M., Pepe, A., et al, 2008. SBAS-DInSAR Analysis of Very Extended Areas: First Results on a $60000-$ km2 Test Site. IEEE Trans. Geosci. Remote Sensing Letters, 5 (3), pp. 438-442. 
Mora, O., Mallorqui, J., Broquetas, A, 2003. Linear and nonlinear terrain deformation maps from a reduced set of interferometric SAR images, IEEE Trans Geosci Remote Sens, 41(10), pp. 2243-2253.

Wu, H., Zhang, Y., Chen, X., et al, 2011. Ground deformation monitoring using small baseline DInSAR technique; A case study in Taiyuan City from 2003 to 2009. Chinese J. Geophys (in Chinese), 54 (3), pp. 673-680.

Zhang, Y., Wu, H., Sun, G., 2012. Deformation model of time series interferometric SAR techniques. Acta Geodaetica et Cartographic Sinica (in Chinese), 41(6), pp. 864-869. 